

\author{
INTERNATIONAL JOURNAL OF \\ EDUCATION, PSYCHOLOGY \\ AND COUNSELLING \\ (IJEPC) \\ $\underline{\text { www.ijepc.com }}$
}

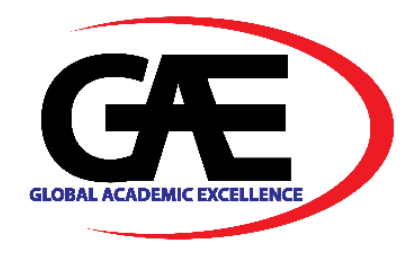

\title{
TEACHERS' SENSE OF SELF-EFFICACY: A STUDY OF ENGLISH TEACHERS IN MALAYSIAN RURAL SCHOOLS
}

Ameiruel Azwan Ab Aziz ${ }^{1}$, Noraini Said ${ }^{2 *}$, Chelster Sherralyn Jeoffrey Pudin ${ }^{3}$, Kamsilawati Kamlun $^{4}$

1 Academy of Language Studies, Universiti Teknologi MARA Cawangan Melaka, Malaysia

Email: ameirul@uitm.edu.my

2 Faculty of Psychology and Education, Universiti Malaysia Sabah, Malaysia

Email: noraini.said@ums.edu.my

3 Faculty of Psychology and Education, Universiti Malaysia Sabah, Malaysia

Email: chelster@ums.edu.my

4 Centre for the Promotion of Knowledge and Language Learning, Universiti Malaysia Sabah, Malaysia

Email:kamsi@ums.edu.my

Corresponding Author

\section{Article Info:}

\section{Article history:}

Received date: 11.09 .2021

Revised date: 10.10 .2021

Accepted date: 15.11 .2021

Published date: 30.11 .2021

\section{To cite this document:}

Aziz, A. A. A., Said, N., Pudin, C. S. J., \& Kamlun, K. (2021). Teachers' Sense Of Self-Efficacy: A Study Of English Teachers In Malaysian Rural Schools. International Journal of Education, Psychology and Counseling, 6 (43), 01-12.

DOI: $10.35631 /$ IJEPC.643001

This work is licensed under CC BY 4.0

\section{Abstract:}

Teaching English as a second language (TESL) in rural schools remains a prominent issue in Malaysia. Many teachers in rural areas struggle with the seemingly insuperable difficulties associated with their underperforming rural schools in English, which is yet to be addressed significantly. This study explores ten English teachers' sense of self-efficacy of those serving in rural schools. The lived experiences of the participants were explored through indepth semi-structured interviews. The data gathered were analysed thematically to gain insights into the phenomenon. Three results of this study revealed the rural environmental influence aspects of teachers' sense of selfefficacy, the context-specific nature of rural teachers' sense of self-efficacy, and the blended philosophical concepts of social support, unswerving commitment, social obligation, and social-emotional benefits as significant driving forces to retain serving rural schools. The study's results could contribute incrementally to the advancement of knowledge on TESL in rural schools by providing insights into the subject and context-specific descriptions.

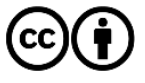


Keywords:

International Journal of

Volume 6 Issue 43 (November 2021) PP. 01-12

DOI 10.35631/IJEPC.643001

Special Issue: Issues and Challenges in English Education

English, Lived Experiences, Teachers' Sense Of Self-Efficacy, Rural Schools

\section{Introduction}

There are countless studies addressing issues of teaching English as a second language (TESL) in rural schools where remarks on disadvantageous of the rural environment and poor performance in public examinations are well documented. Teachers seem to struggle with the insuperable difficulties correlated with their teaching performances, claiming that things do not work quite the same within the context of their counterparts in urban schools (Cheng, Yunus, \& Mohammad, 2016). This is evident in Aziz's (2015) findings that even though the difficulties are considerable for teachers to deal with in general, they are particularly intense for teachers in rural schools. This situation leads to another prominent issue as rural schools face problems retaining high-quality teachers (Aziz, 2015) as they prefer to serve in urban schools (Rao \& Jani, 2011). The high teacher turnover in rural schools has an adverse fiscal impact on Malaysian educational settings. The constant flux of teachers joining and moving out from rural schools has negatively impacted students' achievement and thus widened the disparities of urban and rural schools performances.

While it may be frustrating to note these facts, after all, some positives could be learned from those who have been serving rural schools for quite some time. In particular, to look into their sense of self-efficacy beliefs at work could probably provide insights into the English teaching phenomenon in rural schools. Although many studies have delved into this disconcerting issue, the present study zeroes in on the lived experiences of a particular group of teachers who remain serving in rural schools despite the noted obstacles. The hypothetical assumption is that those who remain in rural schools possess a strong sense of self-efficacy beliefs, and this brings about the possibility that their self-efficacy beliefs are very much alive and that the experiences of teachers led them to come out with their own philosophies, which are more viable within unique rural-teaching contexts.

New contribution of knowledge in understanding the phenomenon of English teaching in rural schools from the teachers' lived experiences is probably more compelling than conventional wide-scale inquiry in the field of TESL. Hence, this study aims to explore the contribution of rural English teachers' lived experiences on forming their sense of selfefficacy beliefs. The crystallising of core philosophies on what heighten and what mitigates teachers' sense of self-efficacy beliefs cannot be something personal but relatively transferable to be learned by others. The literature on TESL in rural schools and teachers' self-efficacy needs more of this. The sharing of compound, personal and professional insights into teachers' lived experiences can lead to a compilation of teachers' sense of self-efficacy notions of what works and what does not in the unique rural context. In the end, this can lead to the transfer of knowledge into the teacher training programme and also teacher professional development courses. This study illuminates English teachers' voices and unearths some commonalities in teachers' sense of self-efficacy beliefs, leading others to develop informed professional development programmes in the future. 




Volume 6 Issue 43 (November 2021) PP. 01-12

DOI 10.35631/IJEPC.643001

Literature Review

Special Issue: Issues and Challenges in English Education

Bandura (1986) proposed the notion that there is a phenomenon known as self-efficacy, a facet in his Social Cognitive Theory. He believed that individuals possess a self-belief about their capability of succeeding in particular tasks based on the triadic reciprocal determinism in shaping human behaviour, which means that the personal, behavioural and environmental factors influence one another in a bidirectional reciprocal way. Bandura (1997) further explained that each individual has a system that allows them to apply self-control measures on the thoughts, feelings, motivations and actions. This system provides a mechanism of selfreflection and set a sub-function to respond to, manage and evaluate the behaviour when reacting to the environment. For example, the interpretation of achievements stimulates an individual to act in self-provided information through self-reactiveness; individuals' ability to construct and regulate appropriate behaviours; and self-reflectiveness; individuals' ability to reflect and evaluate their soundness cognitions and behaviours. This process affects selfconfidence and implements thoughtful and reliable action following the requirements of the environment. Bandura (1986) argued that through self-reflection, each individual could assess the experience and mentality. Self-reflection had a significant impact on the confidence of individuals to form new thoughts and behaviour. As a result, individual behaviour will be predictable through thoughts of individual trust in his ability, compared to the actual results achieved. However, this does not mean that individuals can perform tasks beyond their capabilities by only believing they can do them. Ability in a task requires harmony between self-confidence with the knowledge and skills. Even the self-perception of the individual's ability helps determine what can be done with their knowledge and skills. Through selfefficacy beliefs, one can exercise control over events that affect their lives to the preferred form, aspirations, level of effort and commitment, elasticity of difficulty, weakness against stress and depression, and measures of success (Bandura, 1997). Thus, the individual's selfefficacy enables them to assess the ability to reflect on themselves, the surrounding environment, behaviour and actions in the future.

In the education field, the concept of sense of self-efficacy among teachers was first introduced in the 1960s in Rotter's Social Learning Theory (Tschannen-Moran et al., 1998). In the review of Rotter's work, Tschannen-Moran et al. (1998) explained that if teachers embraced the influence of the environment over their capabilities in shaping students' learning, teachers are displaying their beliefs on the dependency of factors beyond their control in their teaching. On the other hand, teachers who expressed their confidence in dealing with students implied that their work depends on factors within their control. Selfefficacy belief highly influences the decisions, goals, and the amount of effort and time a particular person persist through challenges and difficulties. In the language teaching and learning setting, educators with self-efficacy belief invest more time, effort, energy and are more motivated to accomplish their teaching goals. In short, teachers' beliefs about their ability and control to bring about outcomes in their classroom and the confidence in teaching, in general, formed the concept of teaching efficacy.

Based on this concept of teachers' sense of self-efficacy beliefs, numerous questions arise. One can question teacher training or professional programmes from the basis that if teachers develop their sense of self-efficacy from their own experiences in a particular context; in this study, the rural schools; rather than what has been taught to them. Previous research on teachers' sense of self-efficacy revealed the link between teacher preparation and teachers' 




Volume 6 Issue 43 (November 2021) PP. 01-12

DOI 10.35631/IJEPC.643001

Special Issue: Issues and Challenges in English Education

behaviour issues (Hoy, 2000; Woolfolk \& Hoy, 1990). A study by Skaalvik and Skaalvik (2015) has shown that teachers with a high level of self-efficacy trust their abilities more to respond to the environment and sustain self-control effectively. Self-efficacy may also indirectly affect the stress-burnout relationship through coping strategies as self-efficacy beliefs can influence the kind of coping strategies used to deal with stress to retain in the teaching profession. In another study of ESL teachers' sense of self-efficacy studies, Phan and Locke (2016) conducted a study to investigate the influence of Vietnamese culture in teachers' self-efficacy in teaching English involving eight teachers. The findings of their study suggested that the teachers relied more on social persuasion rather than their mastery experiences to form their self-efficacy in teaching. It is also found that the perception of inequality in power seemed to diminish their self-efficacy. Another finding in this study is that the concern for face loss and public image appeared to impact self-efficacy in teaching English. The dual roles management is also found to be affecting the teachers' efficacy, especially among female teachers who are struggling with different roles at home and the workplace. The findings revealed that certain cultural values appeared to influence the formation of teacher efficacy beliefs.

Nevertheless, even though much can be gleaned from the immense literature on English teachers' sense of efficacy, a lack of attention has been given to studying those serving in rural schools. Shoulder and Krei (2015) noted that only a few studies on teachers' sense of self-efficacy had addressed teachers from rural schools. Although the existing literature has enlightened the scholar world on teachers' sense of self-efficacy in general, much still needs to be learned, and there is great urgency to look deeper into this research area in a specific context of rural schools in Malaysia for more decisive conclusions.

\section{Methodology}

\section{Participants}

This qualitative phenomenological case study explores the lived experiences of English teachers who have served rural schools for more than five years during data collection to elicit rich information on the phenomenon under study. The participants were ten teachers, and all were regarded as senior and experienced teachers. They also have considerable achievements and influence in the field of TESL in rural schools. As the purpose of a phenomenological approach is to gain insights from the lived experiences and perceptions of a specific group of people (Bogdan \& Biklen, 2006) hence, the fact that all ten participants willing to participate in this study convinced us that research on them would be highly informative and contribute to the scanty literature on English teachers' sense of self-efficacy in rural schools.

\section{Data Collection Method and Analysis}

In order to seek answers regarding how the participants go about constructing their selfefficacy beliefs, it would be impossible to break up the phenomenon of teaching the English language from the institutional and instructional context of the academic programme. In other words, the boundary between the phenomenon and its context is distorted. Hence, to explore how participants describe their self-efficacy beliefs, it is best to focus on a single setting or context to gather rich data. In this study, the broader phenomenon-the perception of teaching English in rural schools- is anchored in a programmatic context. 


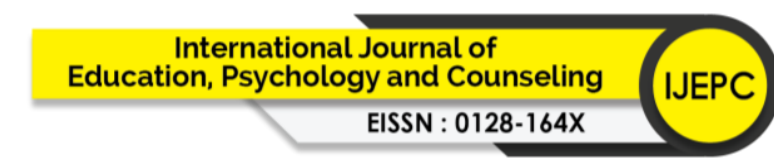

Volume 6 Issue 43 (November 2021) PP. 01-12

DOI 10.35631/IJEPC.643001

Special Issue: Issues and Challenges in English Education

In-depth semi-structured interview data were used to understand participants' lived experiences and perceptions of their self-efficacy beliefs. Semi-structured interviews allow a collection of rich and personalised information and personal perspectives on the outward behaviours of participants (Patton, 2002). They were interviewed following an interview protocol consisting of self-developed open-ended questions in sessions that lasted between 60 to 85 minutes. Field notes were also noted to record non-verbal communication and memo on the interpretation of the responses. The recordings were then transcribed and labelled with pseudonyms (T1, T2, T3 etc.) and were instantly examined to guarantee precise interpretation. The researchers further contacted any unclear responses to procure elucidations in order to avoid assumptions and misinterpretation.

Thematic analysis, known as a method to identify, analyse, and report data themes (Boyatzis, 1998), was used in the study. The analysis is done analytically by systematically evaluating the data set, which allows the researchers to pursue meanings. The data analysis is completed by conducting strategies to establish quality, substantiate data accuracy, methods, meanings, and interpretations verification. The verification procedures were done to establish the trustworthiness of the study's results through member checks and peer debriefing processes. Moreover, triangulation was used to verify, corroborate, and validate evidence and ensure the interpretive validity of data analysis and substantiate the study's results.

\section{Results and Discussion}

The three main themes are as follows:

\section{The Rural Environmental Influence Aspects of Teachers' Sense of Self-Efficacy}

Almost all the ten participants seemed to have had to deal with challenges to work in the rural environment. They seemed to have almost zero exposure in their teaching training programme and were clueless when first sent to rural schools. T1 explained that she was not used to the lifestyle in rural areas as she was raised in an urban area. She already knew it would be a setback to teach in rural schools, and it came to no surprise that she struggled with the new chapter in her life. In the beginning, she could not commit to her teaching as she was emotionally affected. She described her early years in rural schools as not a joy and admitted that she often considered moving to urban areas or quitting teaching entirely.

T3 shared a similar experience and pointed out that the poor environment of rural schools is the contributing factor. She believed "if the environment is good, we all can perform well" (T3/Int1/83), emphasising that she would perform better with better infrastructures and facilities. T3 remarked that there were many times when she could not carry out her lessons as she desired due to the limitations, and she could not do much about it.

The sense of dissatisfaction seems to be in most of these participants. In a similar view, T5 also criticised that the circumstances of the environment in her school affected her teaching duties. T5 said that it was difficult for her to be a competent teacher knowing that she could only teach with limited resources and inadequate support. Comparably, T6 elaborated that her sense of self-efficacy is "dented" (T6/Int2/174) when teachers lack environmental support. For T8, another environmental factor contributing to her sense of self-efficacy is the lack of technology support in rural schools. Acknowledging the demand for 21 st-century teaching 


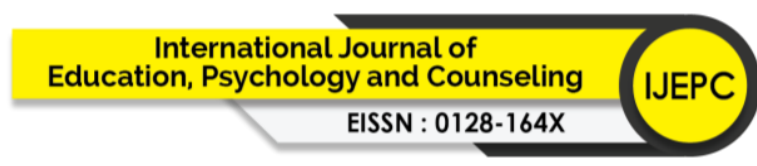

Volume 6 Issue 43 (November 2021) PP. 01-12

DOI 10.35631/IJEPC.643001

Special Issue: Issues and Challenges in English Education and learning, she claimed that the wide use of computer technology in the classroom made her feel worried and insecure because her school could not provide such facilities. T8's vicarious experience made her lose confidence when she "started to see other people using that and using that to teach" and felt "envious sometimes when they used such things, such gadgets" (T8/Int2/67-68).

T8's experiences with teaching English in rural schools best summed in her views her critical emphasise on classroom conduciveness. She believed that both teachers and students should be comfortable in the classroom to be at their best for teaching and learning. T8 believed that without this element, the hindrance of the teaching and learning process is inevitable. In a similar view, T4 and T10 stated that teaching in an "uncomfortable classroom" appeased their sense of self-efficacy. T10 explained that "if you're teaching in an air-conditioned room, comfortable for the students and the teacher, I believe that the teaching will be more efficient because when the students are comfortable, they will behave and will be more interested to learn rather than to be distracted by any other factors. So, yes, definitely environment can influence my teaching" (T10/Int2/70-73). T7 also agreed that rural environmental affected his sense of self-efficacy. He further explicated that due to the situation, he was forced to neglect his lesson plan and "do something else" (T7/Int2/110).

Most of the lived experiences of all ten study participants illustrate what teachers in rural schools face almost every day. Some participants admitted to being emotional and frustrated when the environment is not on their side as they face difficulties to ensure students engagement in their lessons. The disadvantageous rural environment is also recognised to be the cause of students' disruptive behaviour, which in return, time was wasted for classroom management, specifically, to get students to be in order.

A lot of what is shared by the participants resonate with significant findings in the literature addressing teachers' sense of self-efficacy. The decrease in self-efficacy (Mukundan et al., 2015) could come through the exhaustion and depersonalisation dimensions (Skaalvik \& Skaalvik, 2010) as well as the lack of feelings of success and accomplishment (Mukundan \& Khandehroo, 2010). Most crucial within the participants' responses is the strength of their convictions - they believe that the environment in rural schools contributes to forming their sense of self-efficacy. They know what negative aspects of the environment do to their confidence in performing their teaching duties. As Bandura (1986) predicted in his Social Cognitive Theory, it is interesting to note that all participants discussed the significant facets of rural environmental factors in their sense of self-efficacy beliefs.

The analysis tells us that through the years spent in serving rural schools, the participants illustrate the impression of the actual situation in rural schools. Their unique experiences divulge that the environmental factors influence their cognitive and behavioural and impact their sense of self-efficacy. The emphatical explanation of the struggle faced in rural schools cannot be neglected to ensure equity to all teachers, and of course, the students too.

\section{The Context-Specific Nature of Rural Teachers' Sense of Self-Efficacy}

All these ten participants seem to find ways to clarify that not all aspects of rural schools diminish their sense of self-efficacy. The analysis has shown paradoxes in their explanations, either matching their own or adding others' experiences to clarify that their self-efficacy 




Volume 6 Issue 43 (November 2021) PP. 01-12

DOI 10.35631/IJEPC.643001

Special Issue: Issues and Challenges in English Education

beliefs are very much dependent on specific contexts. For instance, T1 emphasised that she felt efficacious to teach in rural schools as she receives robust administrative and collegial supports, specifically through verbal and non-verbal feedback. These supports have helped them to feel appreciated and acknowledged, thus, heightening her sense of self-efficacy. She believed that teachers' sense of self-efficacy could be increased under great leadership and supportive administration. In the same vein, T3 indicated that realistic leaders have helped her perform her teaching tasks. She felt entrusted by her superiors with the liberty to teach without putting too much pressure by setting a realistic goal and asking her to enjoy teaching students. The realistic views have helped her to be confident to continue teaching in the school. Relatively, T9 recounted her experiences and described her superiors as "very pretty much supportive when it comes to English" (T9/Int1/41). Recognising teachers' efforts, for T9, is the utmost crucial gesture that school's administrators could do as it has positive implications in boosting teachers' sense of self-efficacy and motivation. In addition, collegial support is also frequently mentioned by the participants in the study as a factor to keep them efficacious. Most participants highlighted that social persuasion from their colleagues significantly affects their sense of self-efficacy beliefs. For T2, her colleagues were one of the major reasons why she remained in rural schools. She recounted that she felt disappointed in herself for not teaching as she wanted to and was stressed due to work pressure, but her colleagues were there to calm her down and persuade her to stay motivated.

Positive student engagement is another context-specific aspect of rural schools mentioned by many participants to significantly contribute to their sense of self-efficacy. Nevertheless, they emphasised that their confidence to engage students in their lessons also depends on the group of students. For instance, T3 claimed that in her experiences, it was easier to manage rural students as they are obedient compared to their urban counterparts. She added that rural students are not exposed to negative and disruptive behaviours; hence, they behave well in the classroom. Additionally, T7 stated that his devotion to helping students and the belief that he can make a difference in students' learning are the factors of his confidence in engaging students in the classroom. Sharing a similar view, T6 remarked that her devotion to engaging students in her teaching resulted from the profound care and concern for the students she had developed over the years. She believed that she could make a difference in her students' learning, as she termed them "people in need" (T6/Int2/209). Furthermore, she believed that rural teachers could make a difference in students' learning and highlighted that students' involvement in many classroom activities and enthusiasm for learning are two pivotal points to achieving the purpose.

In contrast with the previous results, several participants confessed that there are factors that could alleviate teachers' sense of self-efficacy. T6 stressed that the most contributing factor in decreasing teachers' self-efficacy is when teachers do not receive positive support and acknowledgement. She has experienced many times in her teaching days where she felt her work was not appreciated and triggered self-doubt about her teaching competency. Furthermore, six of the participants viewed themselves as novice teachers as they have less than ten years of teaching experience; hence, they often felt inadequately prepared for the challenges had not developed a schema to cope with what goes on in rural schools, which they could rely on. This is consistent with Shoulders and Krei's (2015) findings that rural teachers who possess more than 15 years of teaching experience seem to be more efficacious. $\mathrm{T} 2$ indicated that it was vital for her to have more teaching experiences and good preparation 


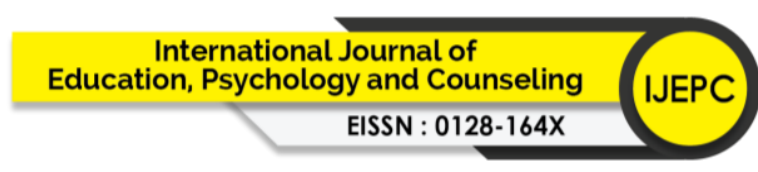

Volume 6 Issue 43 (November 2021) PP. 01-12

DOI 10.35631/IJEPC.643001

Special Issue: Issues and Challenges in English Education to strengthen her instructional strategies before teaching in the classroom. She claimed that she was not confident to teach without enough preparation.

There seem to be unique perspectives from all ten participants about their sense of selfefficacy. All of them firmly remarked that their levels of self-efficacy were varied depending on a context-specific basis. An important revelation in these results is strong relationships between teachers' sense of self-efficacy and the varying amounts of social persuasion through administrative and collegial support, students' engagement, and teaching experiences. All the incidences of lived experiences significantly contribute to the formation of teachers' sense of self-efficacy. While participants have talked a lot about what heightens and mitigates their self-efficacy beliefs, none clearly elaborate the level of rural teachers' sense of self-efficacy, as it is dependable and varied based on a context-specific basis. All the ten participants shared different experiences, particularly in social support; hence, the accumulation of their experiences cannot be generalised into a similar conclusion. Therefore, the existing literature on teachers' sense of self-efficacy cannot be taken as a finite measurement for rural English teachers' sense of self-efficacy as it more aptly fits into the category of "it depends" rather than the category of "compelling reasons".

\section{The Blended Philosophical Concepts of Social Support, Unswerving Commitment, Social Obligation and Social-Emotional Benefits as Significant Driving Forces to Retain Serving Rural Schools}

The path along which participants in this study journeyed toward serving rural schools varied widely. When the question of "Do your sense of self-efficacy keep you teaching in the environment?" was asked to them, none of them gave an answer that was exclusively confined to their sense of self-efficacy. In the hermeneutic encounters with all participants, they have revealed the driving forces that contribute to their decision to continue to serve in rural schools.

All participants emphasised that for rural schools to retain quality English teachers is to find ways to boost teachers' sense of self-efficacy by addressing all issues shared above. However, all of them admitted that it is somewhat unfeasible to improve the rural teaching and learning environment in a short amount of time as it requires a lot of effort and time and involves a considerable financial allocation. What could be done realistically at this point is to offer and provide enough support to teachers to boost their confidence to continue teaching in rural schools. T6 thought that the support should come from the school's community, involving parents, students, administrators, and teachers. She stressed that English teaching is, in fact, everyone's business. Instead of leaving the responsibility to improve students' achievement on the teachers' shoulders, the community should join in hand by extending relevant support to teachers. Similarly, T8 expressed that teachers would be more confident and motivated to remain in rural schools with positive support. She said that the school administrators could help make teachers' work better and more enjoyable with more "support, understanding and trust the teachers" (T8/Int2/203). She believed that such support would create a comfortable atmosphere for teachers and boost their motivation and commitment to continue serving in their schools. 


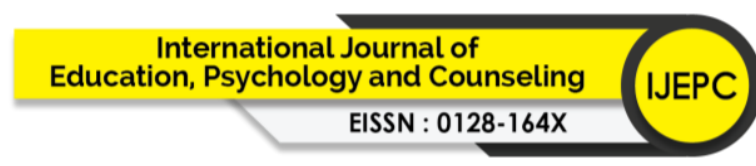

Volume 6 Issue 43 (November 2021) PP. 01-12

DOI 10.35631/IJEPC.643001

Special Issue: Issues and Challenges in English Education

Interestingly, the participants revealed the actual reasons why they persist in rural schools. All the ten participants indicated various factors influencing their sense of self-efficacy to remain serving rural schools. For T1, her unswerving commitment and social obligation to help rural students were the reasons why she stayed. She believed that it would be a great satisfaction if she could help produce excellent students in English, added to the positive reflection and meaning as a teacher. In a similar vein, T3's decision to stay was due to the social-emotional benefits gained through her years spent in rural schools. Making clear of her point, T3 indicated that her successful teaching experiences were the main factor for the decision as she has experienced helping several students score excellently in public examinations, which was way beyond her expectations. Such experience motivated her to keep on going as she believed that she could be of help. She stressed that the successful teaching experiences had heightened her confidence.

T8, T9 and T10 expressed a similar view about their commitments. They made it clear that despite the disadvantageous rural teaching and learning environment, the students still can excel in English as they have experienced helping quite a number of them. They believed that if teachers possess positive sentiments such as being passionate and enthusiastic in teaching, it would significantly contribute to students' success. T6 metaphorically illustrated that teaching in rural schools is like completing a jigsaw puzzle, assembling piece by piece to create a beautiful picture. In the end, similar feelings of emotional satisfaction could be felt by teachers, particularly knowing the fact that they have made a difference in students' life.

It is remarkable to note that there are contradictions from the analysis, which is a surprising revelation of the truth of the phenomenon under study. The results show that the teachers' sense of self-efficacy is formed through individuals' lived experiences and perspectives about their careers. Teachers are thinkers who form philosophies of their own. The analysis shows that the participants have developed a blended philosophical concept of social support, unswerving commitment, social obligation and social-emotional benefits as significant driving forces to retain serving rural schools. All the expressions by the participants signified a special emotion-teacher-student bonding, which is placed as the fundamental element of their lived experiences. This result is a divergence from existing literature, such as the findings in Aziz's (2015) study in retaining quality teachers in rural schools. A crucial revelation from this study is that the accumulation of rural teachers' experiences cannot be generalised into a similar conclusion but instead has to be treated as unique cases. This opens up new opportunities in terms of input towards developing teacher professional development courses and teacher training programmes.

\section{Implications}

The final depiction of the result was through the essence description of participants' selfefficacy beliefs as described in the emerging themes. There will be assumptions based on the emergent themes, which will be valid, as it exists ubiquitously and involve human emotions and feelings.

The responses shared by all participants strengthen the beliefs that lived experiences and personal histories are important. They informed pivotal stories and pointed out pieces of knowledge from a personal point of view. One powerful message from these results is that strong social support should be extended to keep teachers motivated and retain them in rural 


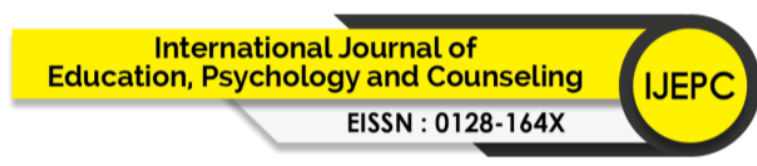

Volume 6 Issue 43 (November 2021) PP. 01-12

DOI 10.35631/IJEPC.643001

Special Issue: Issues and Challenges in English Education schools. As it was the most frequently mentioned by the participants, the results implied that teachers desired to feel appreciated and acknowledged by their administrators. Extending support, verbal and non-verbal, by administrators would positively impact teachers' sense of self-efficacy. Administrators could cater to teachers' needs to be heard, ensure teachers' equity in decision making, show respect and equally treat teachers in the distribution of workload. Another way to heighten their sense of self-efficacy is by extending appreciation through simple gestures such as appreciation notes, compliments or certificates of acknowledgement of their work. Administrators should also participate in the teachers' programmes as much as they can. Their participation would leave positive impacts on teachers' confidence and motivation. Other than that, the results also emphasised the importance of collegial support in enhancing their sense of self-efficacy. Administrators should also be aware of the interactions among the teachers in the school. They must present themselves and participate in the interactions to show their profound care and concern towards the teachers and instil positive teamwork in the school. This could ensure teachers do not feel left alone and boost their self-confidence to perform their teaching duties. Skaalvik and Skaalvik (2015) emphasised that a supportive school environment is indeed a predictive factor of teachers' satisfaction and motivation to stay in the profession.

History teaches. In many of their responses, participants stressed that the accumulation of their experiences is indeed valuable knowledge that should be shared with others, who might have inaccurate views of the phenomenon of English teaching in rural schools. Most participants have shared the reality of the rural teaching and learning environment they were sent to and boldly revealed honest judgments, implying that these perspectives have significant influences on forming their sense of self-efficacy. Hence, this study has gone an extra mile to include aspects of the perspectives of these participants who retain in rural schools and gathered their account of experiences, and the collection of the information should be included in teacher training and teacher professional development programmes. It is advisable to consider these results as consideration of content in the preparation programmes and placed as primary importance. This could assist in ensuring that prospective teachers are more prepared to enter the teaching profession and be sent to rural schools. Such preparations would prepare them from being drained and enlighten them to cope positively with rural schools' challenges.

\section{Limitations and Recommendations}

This study explored teachers' sense of self-efficacy of ten English teachers who retain serving rural schools in Malaysia. There would be constraints on generalisability due to the small scale sample, and the researchers depended on the responses gathered during the interviews. It is acknowledged that the findings are not generalisable beyond the specific population and demographic from which the participants were recruited. It is recommended for future studies to address different samples from other contexts for greater understanding.

Due to researcher bias, there would also be limitations on the utility value of the results and their applications. Creswell (1998) pointed out that researchers display the teachers' perspectives and that of themselves in qualitative research. To claim that this study is biasfree is impossible. The researchers might have unintentionally brought personal biases into analyses and interpretations. Nevertheless, several verification procedures are utilised for reviewing data analysis to ensure the trustworthiness of the study's results. Future studies 




Volume 6 Issue 43 (November 2021) PP. 01-12

DOI 10.35631/IJEPC.643001

Special Issue: Issues and Challenges in English Education could consider employing a quantitative approach to gain more insights from a larger sample to increase credibility and validity.

\section{Conclusion}

The researchers attempted a comprehensive analysis to flesh out the three emergent themes within the responses of ten participants. These themes were then verified by two experts in the field and recognised the consistencies within the contexts.

These results of this study advance the understanding in the field of TESL in rural schools by providing insights into the subject, and context-specific descriptions of the lived experiences and perceptions of the teachers. It is believed that the results are significant as they contributed new knowledge to the body of literature on TESL, specifically in rural education, in-service professional development courses and teacher training programmes. The knowledge generated from this study could offer recommendations for changes in educational practices, in which the authorities, school administrators and teachers could collaborate in improving English education in rural schools and thus positively impact students' learning, achievement and school reputation.

\section{Acknowledgements}

The authors extend special thanks to the committed participants in this study who cordially gave their time and shared their experiences for the interviews, and continued serving their students in rural schools even in this challenging time due. We would like to express our appreciation to Global Academic Excellence (M) Sdn Bhd, who granted us the Publication Grant Scheme.

\section{References}

Aziz, N. (2015). Retaining high-quality teachers in rural primary schools in Malaysia. 4th Annual Southeast Asian Studies Symposium, 46.

Bandura, A. (1986). Social foundations of thought and action: A social-cognitive theory. Englewood Cliffs, NJ.: Prentice-Hall.

Bandura, A. (1997). Self-efficacy: The exercise of control. New York: Freeman.

Bogdan, R. C., \& Biklen, S. K. (2006). Qualitative research for education: An introduction to theories and methods. Boston, MA: Pearson Education, Inc.

Boyatzis, R. (1998). Transforming qualitative information: Thematic analysis and code development. Thousand Oaks, CA: SAGE.

Cheng, L., Yunus, M. M., \& Mohammad, M. (2016). Issues contributing to low performance of English in a national school in Song, Sarawak. International Seminar on Generating Knowledge Through Research (1) (pp. 499-509). Universiti Utara Malaysia.

Hoy, A. (2000). Educational Psychology in Teacher Education. Educational Psychologist 35 (4), 257-270.

Mukundan, J., \& Khandehroo, K. (2010). Burnout Among English Language Teachers in Malaysia. Contemporary Issues In Education Research 3 (1), 71-76.

Mukundan, J., Pezhman, Z., Abdolvahed, Z., Umi Kalthom, A., \& Husniah, S. (2015). Language teacher burnout and school type. English Language Teaching 8 (9), 26-32.

Patton, Q. M. (2002). Qualitative research and evaluation methods. London, UK: Sage. 


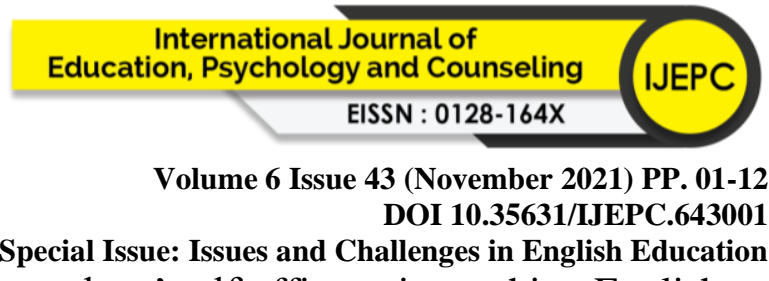

Phan, N. T. T., \& Locke, T. (2016). Vietnamese teachers' self-efficacy in teaching English as a Foreign Language: Does culture matter?. English Teaching: Practice \& Critique (15).

Rao, R., \& Jani, R. (2011). Teacher allocation and equity in Malaysian schools. Institutions and Economics, 103-112.

Shoulders, T., \& Krei, M. (2015). Rural High School Teachers' Self-efficacy in Student Engagement, Instructional Strategies and Classroom Management. American Secondary Education 44(1), 50-61.

Skaalvik, E. M., \& Skaalvik, S. (2015). Job Satisfaction, Stress and Coping Strategies in the Teaching Profession: What Do Teachers Say?. International education studies, 8(3), 181-192.

Skaalvik, E., \& Skaalvik, S. (2010). Teacher self-efficacy and teacher burnout: A study of relations. Teaching and Teacher Education, 26, 1059-1069.

Tschannen-Moran, M., Hoy, A., \& Hoy, W. (1998). Teacher efficacy: Its meaning and measure. Review of Educational Research 68, 202-248.

Woolfolk, A. E., \& Hoy, W. K. (1990). Prospective teachers' sense of efficacy and beliefs about control. Journal of Educational Psychology, 82(1), 81-91. 